\title{
Synthesis and Characterization of Sugarcane Bagasse Based Activated Carbon: Effect of Impregnation Ratio of $\mathrm{ZnCl}_{2}$
}

\author{
Sahira Joshi*1, Bishnu K.C. ${ }^{1}$ \\ ${ }^{1}$ Department of Applied Sciences and Chemical Engineering, Institute of Engineering, \\ Tribhuvan University, Lalitpur, Nepal \\ *CorrespondingE-mail: sjoshi61@hotmail.com \\ (Received: March 28, 2020; Revised: May 31, 2020 \& Accepted: June 16, 2020)
}

\begin{abstract}
Series of activated carbons (ACs) have been prepared from sugarcane bagasse powder by $\mathrm{ZnCl}_{2}$ activation at various impregnation ratios of $\mathrm{ZnCl}_{2}$ to Sugarcane bagasse powder of $0.25: 1,0.5: 1,1: 1$ and 2:1 by weight. Characteristics of the activated carbons (ACs) were determined by iodine number, methylene blue number, surface area, scanning electron microscopy $(\mathrm{SEM})$ and $\mathrm{x}$-ray diffraction. Iodine number $\left(\mathrm{I}_{\mathrm{N}}\right)$ indicated that, microporosity of the $\mathrm{AC}$ were increased with increasing impregnation ratio $\mathrm{ZnCl}_{2}$ to Sugarcane bagasse upto 1:1 then started to decrease. However, mesoporosity as well as surface area was increased progressively. The maximum value of iodine number $(868 \mathrm{mg} / \mathrm{g})$ was achieved in the AC prepared at impregnation ratio of $\mathrm{ZnCl}_{2}$ to Sugarcane bagasse of 1:1. SEM micrographs also show the presence of well developed pores on its surface of AC-1. The broad peaks in the XRD patterns indicated that, all the ACs is amorphous materials. From results, it is concluded that $\mathrm{ZnCl}_{2}$ concentration used in impregnation is effective for development of porosity and surface area of the AC prepared from sugarcane bagasse.
\end{abstract}

Keywords: Activated carbon, sugarcane bagasse, zinc chloride, impregnation ratio

\section{Introduction}

Activated carbon (AC) is a porous carbonaceous material with the highly developed surface area and most commonly used adsorbent for removal of pollutants of inorganic and organic compounds. Its adsorptive properties are associated with surface area, pore volume, pore size distribution and the presence of functional groups. Moreover, the pore size distribution with the combinations of the micropores (pore diameter $<2 \mathrm{~nm}$ ) and mesopores (pore diameter 2-50 nm) are responsible to improve the transportation process of particles or molecules inside porous networks [1]. Today, activated carbon (AC) is used in a wide range of industrial applications, including uses, gas storage, pollutant and odor removal, gas separations, catalysis, gas purification, metal extraction, water purification, chromatographic separation, super-capacitors, electrodes, gas storage etc [2].
Chemical activation method is commonly used to produce $\mathrm{AC}$ from carbonaceous materials. In chemical activation, the precursor material is impregnated with a chemical (activating) agent and the impregnated product is carbonized at relatively lower temperatures 400-600 ${ }^{\circ} \mathrm{C}$ in inert atmosphere [3]. The chemical (activating) agents help to develop porosity in the $\mathrm{AC}$ by means of dehydration and degradation [4]. The advantages of the chemical activation over physical activation are lower activation temperatures, shorter activation times, a single activation step (simultaneous carbonization-activation), higher AC yields, a large surface area and well-developed microporosity [5]. From the various activating agents, $\mathrm{H}_{3} \mathrm{PO}_{4}$ and $\mathrm{ZnCl}_{2}$ are preferred for the activation of lignocellulosic materials [6]. $\mathrm{ZnCl}_{2}$ is commonly used as an activating agent in $\mathrm{AC}$ production, especially with lignocellulosic biomass to obtain AC with high surface area [7]. 
The textural and chemical properties of the prepared AC depend on the nature of precursor used, carbonization temperature, time and preparation conditions. Of these, impregnation is one of the most influential factors in the development of porous structure, formation of more char and the surface morphology of AC [8]. Many studies have been performed to determine the effect of all preparation parameters on the characteristics of AC. Caturla et al. [9] studied the effect of impregnation with $\mathrm{ZnCl}_{2}$ in the activation of peach stones and found that the amount of $\mathrm{ZnCl}_{2}$ used for impregnation was the most major factor leading the textural properties (specific surface area and micropore size distribution) of the AC. Boudrahem et al. [10] used coffee residue in the preparation of powder AC by chemical activation with zinc chloride. They found that, higher impregnation ratios promoted pore widening, resulting in a mesoporous carbon. Moreno-Piraján and Giraldo [11] prepared ACs by pyrolysis of cassava peel at different impregnation ratios in presence of $\mathrm{ZnCl}_{2}$. They observed that, the impregnation ratio of $\mathrm{ZnCl}_{2}$ to precursor had a strong influence on the pore structure of these ACs. Low impregnation ratio of $\mathrm{ZnCl}_{2}$ to precusor lead to essentially microporous ACs, intermediate impregnation ratios show wider pore size distribution (from micropores to mesopores) in $\mathrm{AC}$ and high impregnation ratios yields essentially mesoporous carbons with high surface area and pore volume. $\mathrm{Hu}$ et al. [12] reported that, when the ratio of activating agent to precursor was higher than 2:1, many micropores were enlarged to mesopores in AC prepared from coconut shell using $\mathrm{ZnCl}_{2}$ as an activating agent.

In recent years, agricultural wastes have also attracted much attention for preparation of AC because of abundant, renewable and available at low cost. Various agricultural waste has been reported for preparation of AC such as peach stone, cassava peel, coconut shell, macadamia nutshell etc $[9,11,12,13]$. In the present study, sugarcane (Saccharum officinarum) bagasse, dry pulpy fibrous residue that remains after crush of sugarcane stalks is most common agricultural wastes of Nepal. Nepal produces tons of sugarcane bagasse in a year [14]. The sugar manufacturing factories located in Terai, Nepal dispose tons of sugarcane bagasse (Gramineae Saccharum officinarum L.) to the surrounding region yearly. The improper disposal of these wastes can lead to inconvenience, environmental pollution and consequently health hazards in that region. This locally-available agricultural waste material can be utilized and converted into highly porous functional activated carbon. The aim of this study was to explore the effect of impregnation ratio of $\mathrm{ZnCl}_{2}$ on the characteristics of AC prepared from sugarcane bagasse (SB).

\section{Materials and Methods}

Sugarcane bagasses were collected from local market of Kathmandu. All the chemicals used were of analytical grade. The nitrogen gas is of ultra high pure (UHP) grade. Zinc chloride $\left(\mathrm{ZnCl}_{2}\right)$ was supplied by Merck, Mumbai, India. The stock solution of methylene blue was prepared by dissolving $1 \mathrm{~g}$ methylene blue in water which is then made up to $1000 \mathrm{~mL}$. Standard solutions of appropriate concentrations were prepared by dilution of the stock solution. Distilled water was used for all the experimental purposes.

\section{Preparation of activated carbon}

Sugarcane bagasses were first washed with tap water then with distilled water, dried in an oven at 110 ${ }^{\circ} \mathrm{C}$ for 12 hours. The dried materials were crushed, powdered with mortar and electric grinder. The sugarcane bagasse powder was sieved to obtain the particles of uniform size of $312 \mu \mathrm{m}$. The powder was mixed with $\mathrm{ZnCl}_{2}$ at different impregnation ratio of $\mathrm{ZnCl}_{2}$ to sugarcane bagasse powder of $0.25: 1,0.5: 1$, $1: 1$ and $2: 1$ by weight. Some distilled water was added to each of these mixtures. The mixtures were heated in hot plate till partly dry mass was obtained and then placed inside an oven for 24 hours at $100{ }^{\circ} \mathrm{C}$. The dried mixtures were separately transferred to a quartz tube, placed in horizontal tubular furnace (Accumax, India) and carbonized at $400{ }^{\circ} \mathrm{C}$ under continuous flow of nitrogen gas at flow rate of $100 \mathrm{~mL} / \mathrm{min}$, for $3 \mathrm{hrs}$. The resultant AC was treated with $0.1 \mathrm{M} \mathrm{HCl}$ and then washed with warm distilled water to remove different residual organic and mineral matter. The ACs were separately washed with cold water till the solution becomes neutral. Finally the samples were dried for 24 hours at $100{ }^{\circ} \mathrm{C}$ inside an air oven and packed in an air tight container. List of the $\mathrm{ZnCl}_{2}$ activated sugarcane bagasse carbons prepared at 
different impregnation ratio of $\mathrm{ZnCl}_{2}$ to sugarcane bagasse is shown in Table 1.

\section{Characterization of activated carbon}

Iodine number of ACs was determined according to ASTM D4607-94 method [15]. Methylene blue number of ACs was determined by single point adsorption isotherm studies according to standard method [16]. Surface area of ACs was estimated by iodine and methylene blue numbers using multiple regressions [17].

Table 1: List of the $\mathrm{ZnCl}$, activated sugarcane bagasse carbons prepared at different impregnation ratio of $\mathrm{ZnCl}_{2}$ to sugarcane bagasse

\begin{tabular}{lllll}
\hline $\begin{array}{l}\text { Activated } \\
\text { carbon }\end{array}$ & $\begin{array}{l}\text { Ratio of } \mathbf{Z n C l}_{2} \\
\text { to sugarcane } \\
\text { bagasse }\end{array}$ & $\begin{array}{l}\text { Carbonization } \\
\text { temp. }\left({ }^{\circ} \mathrm{C}\right)\end{array}$ & $\begin{array}{l}\text { Carbonization } \\
\text { time }(\mathrm{hr})\end{array}$ & $\begin{array}{l}\text { Size } \\
(\boldsymbol{\mu m})\end{array}$ \\
\hline $\begin{array}{l}\mathbf{A C} \\
\mathbf{- 0 . 2 5}\end{array}$ & $0.25: 1$ & 400 & 3 & 212 \\
$\mathbf{A C} \mathbf{- 0 . 5}$ & $0.5: 1$ & 400 & 3 & 212 \\
$\mathbf{A C} \mathbf{- 1}$ & $1: 1$ & 400 & 3 & 212 \\
$\mathbf{A C}-\mathbf{- 2}$ & $2: 1$ & 400 & 3 & 212 \\
\hline
\end{tabular}

The surface morphology of ACs was studied by scanning electron microscope (SEM), Hitachi Co. Ltd., Japan. Structural analysis was carried out by powder X-ray diffraction (XRD) using Rigaku (Miniflex II, Rigaku, Tokyo, Japan) using $\mathrm{CuK} \alpha$ radiation $(\lambda=1.54056 \AA)$ radiation at a scanning rate of $1^{\circ} \mathrm{min}^{-1}$.

\section{Results and Discussion}

\section{Characterization of activated carbon: Iodine number $\left(\mathrm{I}_{\mathrm{N}}\right)$, methylene blue number $\left(\mathrm{MB}_{\mathrm{N}}\right)$ and surface area}

$\mathrm{I}_{\mathrm{N}}, \mathrm{MB}_{\mathrm{N}}$ and surface area of the $\mathrm{ZnCl}_{2}$ activated sugarcane bagasse carbons prepared at different impregnation ratio of $\mathrm{ZnCl}_{2}$ to sugarcane bagasse are shown in Figure 1 and Figure 2 respectively. Iodine number $\left(\mathrm{I}_{\mathrm{N}}\right)$ gives a measure of the micropore $(0$ to $20 \AA$ ) content of the AC. It is the milligram of iodine adsorbed onto $1.0 \mathrm{~g}$ of adsorbent [15]. Likewise, methylene blue number $\left(\mathrm{MB}_{\mathrm{N}}\right)$ measures the mesopore (20 to $50 \AA$ ) content. $\mathrm{MB}_{\mathrm{N}}$ is the milligram of methylene blue adsorbed onto $1.0 \mathrm{~g}$ of adsorbent [16]. As shown in Figure 1 and 2, $\mathrm{I}_{\mathrm{N}}$ and surface area of AC increased with increase in impregnation ratio from $0.25: 1$ to $1: 1$ but decreased after further increase in impregnation ratio to $2: 1$. However, $\mathrm{MB}_{\mathrm{N}}$ of $\mathrm{AC}$ was

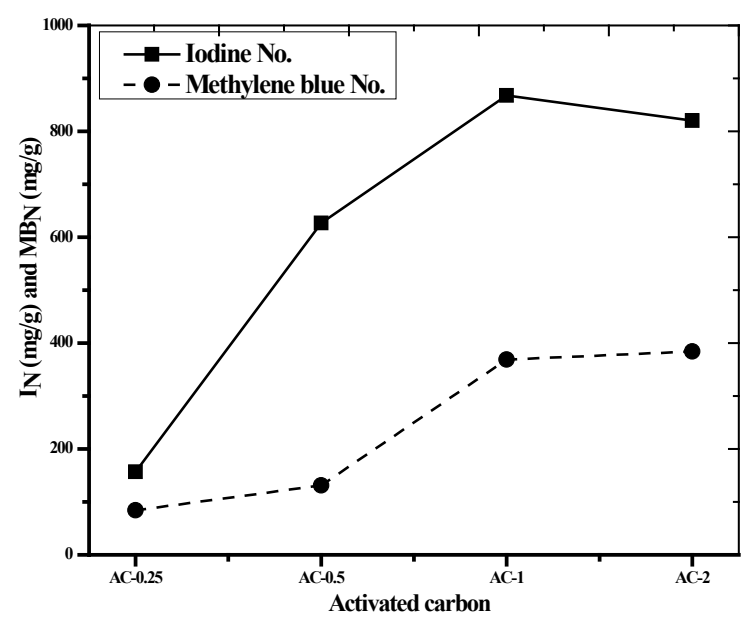

Figure 1: $I_{N}$ and $M B_{N}$ of the $\mathrm{ZnCl}_{2}$ activated sugarcane bagasse carbons prepared at different impregnation ratio of $\mathrm{ZnCl}_{2}$ to sugarcane bagasse

found to be increased with increasing impregnation ratio of $\mathrm{ZnCl}_{2}$ to sugarcane bagasse continuously. The highest iodine number of $868 \mathrm{mg} / \mathrm{g}$ was achieved at the impregnation ratio of $\mathrm{ZnCl}_{2}$ to sugarcane bagasse

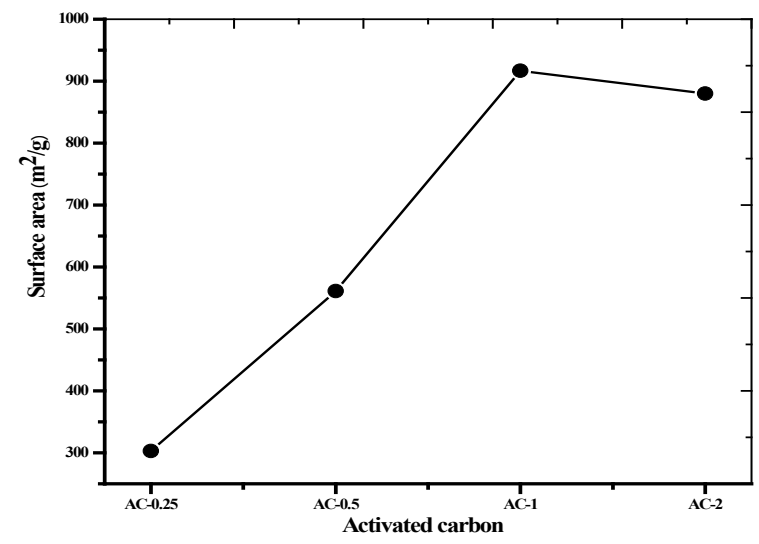

Figure 2: Surface area of the $\mathrm{ZnCl}_{2}$ activated sugarcane bagasse carbons prepared at different impregnation ratio of $\mathrm{ZnCl}_{2}$ to sugarcane bagasse

of 1:1. Hence, the optimum impregnation ratio of $\mathrm{ZnCl}_{2}$ to sugarcane bagasse for the preparation of AC is $1: 1$.

During the chemical activation of lignocellulosic materials by $\mathrm{ZnCl}_{2}$, it acts as a dehydration agent. Impregnation of $\mathrm{ZnCl}_{2}$, first results in degradation of the material and, on carbonization, the material undergoes dehydration process. It leads in charring and aromatization of the carbon skeleton and creation of pore structure [9]. Also, molecular hydrogen is evolved from the hydroaromatic structure of the 
precursor and leaves behind some sites for reaction [18]. With increase in impregnation ratio $0.25: 1$ to 1.1 , the activating agent, $\mathrm{ZnCl}_{2}$ increases the discharge of volatile matter from the carbon surface. It promotes the formation of new pores and the widening of existing pores, resulting in an improvement of micro, mesoporosity and surface area. Consequently, $I_{N}$, $\mathrm{MB}_{\mathrm{N}}$ and surface area of AC are gradually increased. With the further increase in impregnation ratio, more volatile matter is released and more carbon burn-off takes place. It leads to more mesopores and macropores in the $\mathrm{AC}$ resulting in a decrease in $\mathrm{I}_{\mathrm{N}}$ and a slight increase in $\mathrm{MB}_{\mathrm{N}}$. It indicated that, the impregnation ratio $\left(\mathrm{ZnCl}_{2} /\right.$ sugarcane bagasse) significantly affects micro and mesoporosity of the sugarcane bagasse ACs. Similar results have also been achieved for the effect of impregnation ratio on the pore structure of $\mathrm{ZnCl}_{2}$ activated AC prepared from lignin [19].

\section{Scanning electron microscope (SEM)}

Scanning electron microscopy (SEM) was used to observe the surface physical morphology of prepared AC samples. Scanning electron micrographs of the $\mathrm{ZnCl}_{2}$ activated sugarcane bagasse carbons prepared at different impregnation ratio of $\mathrm{ZnCl}_{2}$ to sugarcane bagasse are shown in Figure 3.

It can be seen from the SEM images, that there are significant differences in the surface morphology of the ACs prepared at different impregnation ratio. The surface of AC-0.25 was found to be smooth with no significant pores. The surface of AC- 0.5 was rough with few tiny pores but not clear. The surface of the AC-1 was filled with pores of different shape and sizes. However, in SEM image of the AC-2, only few pores were seen. In the chemical activation process, pore diameter and pore volume increase and new pores are created due to the reaction between lignocellulosic material and activating agent. Upon increasing the impregnation ratio from $0.25: 1$ to $1: 1$, the pore diameter enlarges continuously and new micropores are generated. For carbons with higher impregnation ratio of 2:1, an excessive amount of $\mathrm{ZnCl}_{2}$ destroyed the porous structure. This result is also supported by iodine and methylene blue numbers. It indicated that, surface morphology of the sugarcane bagasse ACs is highly influenced by the impregnation ratio $\left(\mathrm{ZnCl}_{2} /\right.$ sugarcane bagasse).
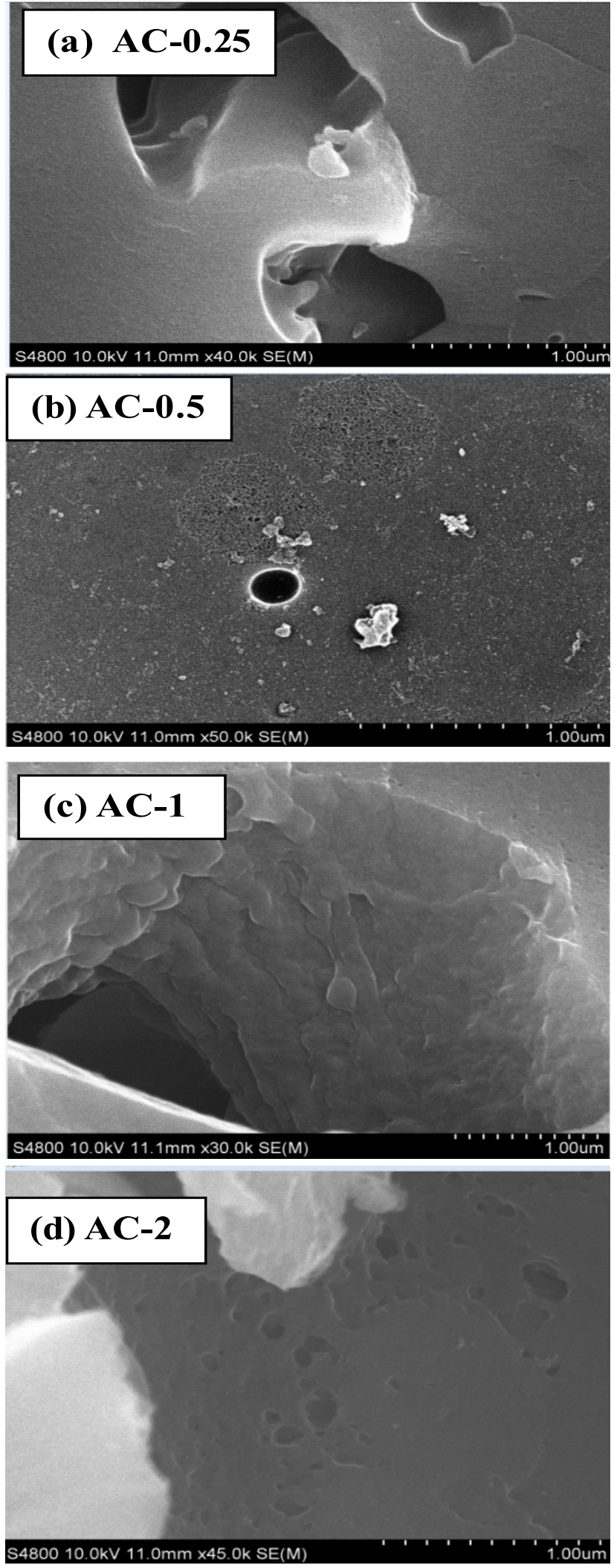

Figure 3: SEM images of $\mathrm{ZnCl}_{2}$ activated sugarcane bagasse carbons prepared at impregnation different ratio of $\mathrm{ZnCl}_{2}$ to sugarcane bagasse (a) 0.25:1 (b) 0.5:1 (c) 1:1 and (d) 2:1 


\section{X-ray diffraction (XRD)}

$\mathrm{X}$-ray diffraction is a common technique to show whether the material is crystalline or amorphous. XRD pattern of crystalline material shows sharp peaks while that of amorphous shows single broad diffused peak. The XRD patterns of the $\mathrm{ZnCl}_{2}$ activated sugarcane bagasse carbons prepared at different impregnation ratio of $\mathrm{ZnCl}_{2}$ to sugarcane bagasse are shown in Figure 4.

XRD patterns of sugarcane bagasse ACs showed two

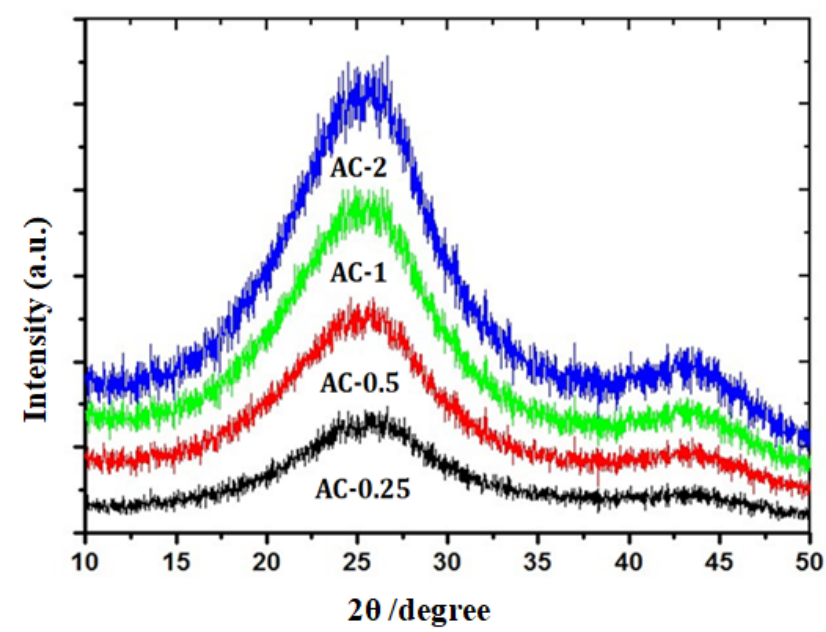

Figure 4: XRD patterns of activated carbon prepared from sugarcane bagasse at different impregnation ratio of $\mathrm{ZnCl}_{2}$ to sugarcane bagasse a) $0.25: 1$ b) $0.5: 1$ c) $1: 1$ and d) $2: 1$

diffraction peaks at around $2 \theta=25^{\circ}$, and $43^{\circ}$ correspond to the reflections of the (002) and (100) planes, respectively. They do not possess long periodicity (no long range order). These hump shaped broad peak in the XRD pattern indicated the amorphous and graphitic nature of the materials, respectively [20]. All the ACs showed a similar diffraction pattern regardless of the different impregnation of $\mathrm{ZnCl}_{2}$ to sugarcane bagasse. It suggested that, all the ACs are amorphous in nature and the graphite crystallite structure of sugarcane bagasse based ACs is not affected by the impregnation ratio $\left(\mathrm{ZnCl}_{2} /\right.$ sugarcane bagasse). The result is similar with the X-ray diffraction pattern of $\mathrm{NaOH}$ activated Lapsi seed stone [21].

\section{Conclusion}

A series of $\mathrm{ZnCl}_{2}$ activated ACs was prepared using sugarcane bagasse at different impregnation ratio of $\mathrm{ZnCl}_{2}$. Iodine number and methylene blue number indicated that, microporosity and surface area of the AC increased gradually upto impregnation ratio of
$1: 1$, and then decreased with increasing impregnation ratio of $\mathrm{ZnCl}_{2}$. On the other hand, the mesoporosity of the AC samples increased continuously. The AC showed highest microporosity at an impregnation ratio of $\mathrm{ZnCl}_{2}$ to sugarcane bagasse powder 1:1. SEM image suggested that, the surface morphology of the ACs are notably affected by impregnation ratio $\left(\mathrm{ZnCl}_{2}\right.$ /sugarcane bagasse). As shown by $\mathrm{X}$-ray diffraction patterns, the impregnation ratio $\left(\mathrm{ZnCl}_{2} /\right.$ sugarcane bagasse) does not make any considerable differences in crystalline/amorphous structure of ACs. Based on these results, it can be concluded that, the impregnation ratio of the activating agent to precursor has a considerable effect on the porosity development in the sugarcane bagasse based activated carbon.

\section{Acknowledgement}

The authors gratefully acknowledge the financial support from the University Grants Commission (UGC) CRG 73/74-Engg-02, Sanothimi, Nepal for financial support for this work.

\section{References}

1. A. Allwar, A. M. Noor and M. A. B. M. Nawi, Textural characteristics of activated carbons prepared from oilpalm shells activated with $\mathrm{ZnCl}_{2}$ and pyrolysis under nitrogen and carbon dioxide, Journal of Physical Science, 2008, 19 (2), 93-104.

2. J. F. Kwiatkowski, Activated Carbons, Classifications, properties and applications, Nova Science Publishers, New York, NY, USA, 2011, ISBN 1620816660, 9781620816660.

3. H. Marsh and F. Rodriguez-Reinoso, Activated Carbon. $1^{\text {st }}$ Ed., Elsevier. London, U.K, 2006, ISBN 9780080444635.

4. M. Kilic, E. Apaydın-Varol and A. E. Putun, Preparation and surface characterization of activated carbons from Euphorbia rigida by chemical activation with $\mathrm{ZnCl}_{2}, \mathrm{~K}_{2} \mathrm{CO}_{3}, \mathrm{NaOH}$ and $\mathrm{H}_{3} \mathrm{PO}_{4}$, Applied Surface Science, 2012, 261, 247-254.

5. D. Krishnaiah, A. Bono, S. M. Anisuzzaman, C. Joseph, T. B. Khee, Carbon dioxide removal by adsorption, Journal of Applied Sciences, 2014, 
14 (23), 3142-3148.

6. Z. Al-QodahI and R. Shawabkah, Production and characterization of granular activated carbon from activated sludge, Brazilian Journal of Chemical Engineering, 2009, 26 (1), $127-$ 136.

7. Z. Liu, Y. Huang and G. Zhao, Preparation and characterization of activated carbon fibers from liquefied wood by $\mathrm{ZnCl}_{2}$ activation, Bio Resources, 2016, 11, 3178-3190.

8. S. Bhati, J. S. Mahur, Savita Dixit and O. N. Chobey, Study on effect of chemical impregnation on the surface and porous characteristics of activated carbon fabric prepared from viscose rayon, Carbon Letters, 2014, 15(1), 45-49.

9. F. Caturla, M. Molina-Sabio and F. RodríguezReinoso Preparation of activated carbon by chemical activation with $\mathrm{ZnCl}_{2}$, Carbon, 1991, 29, 999-1007.

10. F. Boudrahem, F. Aissani-Benissad and H. AitAmar, Batch sorption dynamics and equilibrium for the removal of lead ions from aqueous phase using activated carbon developed from coffee residue activated with zinc chloride, Journal of Environmental Management, 2009, 90(10), 3031-3039.

11. J. C. Moreno-Piraján and L. Giraldo, Study of activated carbons by pyrolysis of cassava peel in the presence of chloride zinc, Journal of Analytical and Applied Pyrolysis, 2010, 87(2), 288-290.

12. Z. Hu, M. P. Srinivasan and Y. Ni, Novel activation process for preparing highly microporous and mesoporous activated carbons, Carbon, 2001, 39 (6), 877-886.

13. A. Ahmadpour and D. D. Do, The preparation of activated carbon from macadamia nutshell by chemical activation, Carbon, 1997, 35 (12), 1723-1732.

14. P. R. Neupane, T. N. Maraseni and M. Koehl, The sugarcane industry in Nepal: Opportunities and challenges, Environmental Development,
2017, 24, 86-98.

15. Annual Book of ASTM Standards, Standard test method for determination of iodine number of activated carbon, ASTM D4607-94, Philadelphia PA, United State of America, 2006.

16. F. Raposo, M. A. D. L. Rubia and R. Borja, Methylene blue number as useful indicator to evaluate the adsorptive capacity of granular activated carbon in batch mode: Influence of adsorbate/adsorbent mass ratio and particle size, Journal of Hazardous Materials, 2009, 165 (13), 291-299.

17. N. A. Cleiton, and M. C. Guerreiro, Estimation of surface area and pore volume of activated carbons by methylene blue and iodine numbers, Quimica Nova, 2011, 34 (3), 472-476.

18. S. Ucar, M. Erdem, T. Tay and S. Karagoz, Preparation and characterization of activated carbon produced from pomegranate seeds by $\mathrm{ZnCl}_{2}$ activation, Applied Surface Science, 2009, 255(21), 8890-8896.

19. M. A. Bedmohata, A. R. Chaudhari, S. P. Singh, and M. D. Choudhary, Adsorption capacity of activated carbon prepared by chemical activation of lignin for the removal of methylene blue dye, International Journal of Advanced Research in Chemical Science, 2015, 2 (8), 1-13.

20. H. Shang, Y. Lu, F. Zhao, C. Chao, B. Zhang, and H. S. Zhang, Preparing high surface area porous carbon from biomass by carbonization in a molten salt medium. RSC Advances, 2015, 5 (92), 75728-75734.

21. S. Joshi, L. K. Shrestha, Y. Kamachi, Y. Yamauchi, M. A. Pradhananga, B. P. Pokhrel, K. Ariga and R. R. Pradhananga, Sodium hydroxide activated nanoporous carbon based on Lapsi seed stone, Journal of Nanoscience and Nanotechnology, 2015, 15 (2), 1465-1472. 